\title{
Transnasal endoscopic approach for pediatric skull base lesions: a case series
}

\author{
Jennifer L. Quon, MD, ${ }^{1}$ Lily H. Kim, BA, ${ }^{1}$ Peter H. Hwang, MD, ${ }^{2}$ Zara M. Patel, MD, ${ }^{2}$ \\ Gerald A. Grant, MD, ${ }^{1,3}$ Samuel H. Cheshier, MD, ${ }^{1,3}$ and Michael S. B. Edwards, MD ${ }^{1,3}$ \\ 1Department of Neurosurgery and 2Division of Rhinology, Department of Otolaryngology-Head and Neck Surgery, Stanford \\ University School of Medicine, Palo Alto; and 'Division of Pediatric Neurosurgery, Lucile Packard Children's Hospital, Stanford, \\ California
}

OBJECTIVE Transnasal endoscopic transsphenoidal approaches constitute an essential technique for the resection of skull base tumors in adults. However, in the pediatric population, sellar and suprasellar lesions have historically been treated by craniotomy. Transnasal endoscopic approaches are less invasive and thus may be preferable to craniotomy, especially in children. In this case series, the authors present their institutional experience with transnasal endoscopic transsphenoidal approaches for pediatric skull base tumors.

METHODS The authors retrospectively reviewed pediatric patients (age $\leq 18$ years) who had undergone transnasal endoscopic transsphenoidal approaches for either biopsy or resection of sellar or suprasellar lesions between 2007 and 2016. All operations were performed jointly by a team of pediatric neurosurgeons and skull base otolaryngologists, except for 8 cases performed by one neurosurgeon.

RESULTS The series included 42 patients between 4 and 18 years old (average 12.5 years) who underwent 51 operations. Headache (45\%), visual symptoms (69\%), and symptoms related to hormonal abnormalities (71\%) were the predominant presenting symptoms. Improvement in preoperative symptoms was seen in $92 \%$ of cases. Most patients had craniopharyngiomas $(n=16)$, followed by pituitary adenomas $(n=12)$, Rathke cleft cysts $(n=4)$, germinomas $(n=4)$, chordomas $(n=2)$, and other lesion subtypes $(n=4)$. Lesions ranged from 0.3 to $6.2 \mathrm{~cm}$ (median $2.5 \mathrm{~cm})$ in their greatest dimension. Gross-total resection was primarily performed (63\% of cases), with 5 subsequent recurrences. Nasoseptal flaps were used in $47 \%$ of cases, fat grafts in $37 \%$, and lumbar drains in $47 \%$. CSF space was entered intraoperatively in 15 cases, and postoperative CSF was observed only in lesions with suprasellar extension. There were 8 cases of new hormonal deficits and 3 cases of new cranial nerve deficits. Length of hospital stay ranged from 1 to 61 days (median 5 days). Patients were clinically followed up for a median of 46 months (range 1-120 months), accompanied by a median radiological follow-up period of 45 months (range 3.8-120 months). Most patients (76\%) were offered adjuvant therapy.

CONCLUSIONS In this single-institution report of the transnasal endoscopic transsphenoidal approach, the authors demonstrated that this technique is generally safe and effective for different types of pediatric skull base lesions. Favorable effects of surgery were sustained during a follow-up period of 4 years. Further refinement in technology will allow for more widespread use in the pediatric population.

https://thejns.org/doi/abs/10.3171/2019.4.PEDS18693

KEYWORDS transnasal endoscopic approach; sellar neoplasm; suprasellar neoplasm; skull base lesion; pediatric neurosurgery; surgical technique

$\mathrm{T}$ RANSNASAL endoscopic approaches are well established in the adult literature as a means of resecting sellar, suprasellar, and parasellar tumors. ${ }^{5,12}$ Over the past century, transsphenoidal approaches have evolved significantly. ${ }^{13}$ The sublabial transsphenoidal approach used by Harvey Cushing and the early transnasal techniques developed by Hirsh were initially devised to reach pituitary tumors primarily within the sellar region. ${ }^{13}$ Since then, the extended transnasal transsphenoidal route has been used for a variety of other skull base pathologies. ${ }^{12}$ The development of this surgical approach has been concurrent with advancements in microscopic and endoscopic technology, allowing improved visualization through a narrow opening. ${ }^{3,13}$ Compared with the microscope, dif- 
ferently angled lens endoscopes offer a wider field of view for the resection of parasellar and suprasellar lesions. ${ }^{5,14}$

Unlike in adults, for pediatric skull base lesions a craniotomy has been the favored approach until recently. The transnasal endoscopic approach may be limited by pediatric anatomy such as an absent or incompletely pneumatized sella, narrow intercarotid distance, and small nares and nasal passages. However, this approach has the benefit of avoiding possible damage to surrounding structures from retraction during subfrontal or pterional craniotomy ${ }^{17}$ and disruption of dentition or facial development. ${ }^{4}$ We report our institutional experience of pediatric skull base lesions approached using a transnasal endoscopic route. We believe that this is a safe yet efficacious alternative to the traditional transcranial approach.

\section{Methods}

We performed a retrospective review of all pediatric patients who underwent transnasal endoscopic approaches for skull base lesions at our institution between 2007 and 2016. All patients were younger than 18 years at the time of their first operation. Patients were identified from a database of patients operated on by the pediatric neurosurgeons at our institution (M.S.B.E., G.A.G., and S.H.C.) and with billing codes for excision of pituitary tumor by transnasal approach (61548); neuroendoscopy, intracranial, with excision of pituitary tumor, transnasal or transsphenoidal approach (62165); craniofacial approach to intradural lesion of anterior cranial fossa (61583); malignant neoplasm of pituitary gland and craniopharyngeal duct (194.3); benign neoplasm of pituitary gland and craniopharyngeal duct (227.3); or neoplasm of uncertain behavior of pituitary gland and craniopharyngeal duct (237.0). Billing code 61548 is generally reserved for microscopic cases, but at our institution, all endoscopic cases were initially scheduled with the use of microscopes during the transitory phase. Therefore, we included 5 cases in which both a microscope and an endoscope were used but not the cases in which a microscope was used alone or as the primary means of visualization. We included patients who had undergone previous operations at our institution or elsewhere. We additionally excluded cases with 1) sublabial approaches or extension beyond a transnasal approach, 2) transnasal endoscopic approaches employed for nonneurosurgical lesions (e.g., located primarily within the nasal cavity), and 3) transnasal endoscopic procedures planned as a combined approach with a concurrent or anticipated craniotomy.

Clinical information for each patient was obtained from a de-identified chart review tool. We analyzed the pre- and postoperative neurological status. All patients underwent a complete workup by a pediatric endocrinologist and ophthalmologist when visual symptoms or signs were present. Some patients also received neuro-oncology and radiation oncology evaluations. All patients underwent preoperative and postoperative MRI with and without contrast within 24 hours of the procedure. The majority of patients underwent serial MRI at regular intervals. The preoperative T2weighted (or, if unavailable, T1-weighted) coronal MR image was used to measure the intercarotid distance (Fig. 1).

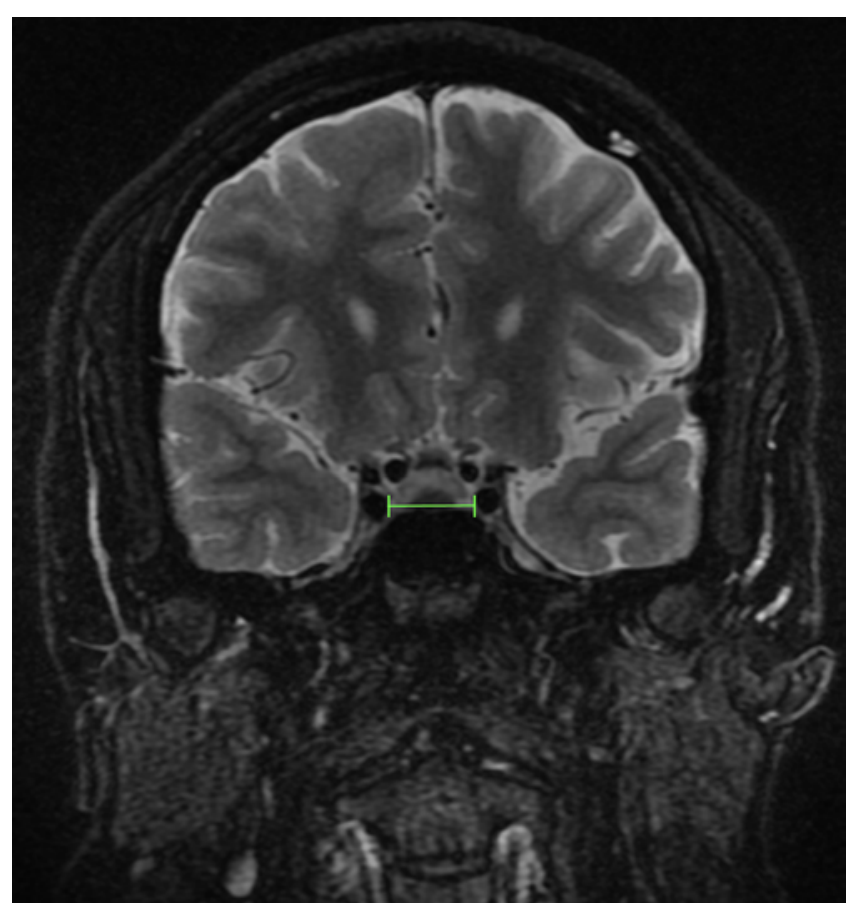

FIG. 1. Preoperative coronal T2-weighted MR image showing the measurement of the cavernous intercarotid distance (line). Figure is available in color online only.

A method previously described in the literature was used to locate and measure the distance between the cavernous segments of the internal carotid arteries ${ }^{26}$ Operative time was gathered from anesthesia records except in cases in which the operations occurred before the full transfer to the electronic medical record system. CSF leak was defined as postoperative leakage of CSF requiring further surgical management. Recurrences were assessed only for gross-total resection (GTR) cases, as subtotal resections (STRs) and biopsy, by definition, result in residual lesions.

Institutional review board approval was obtained to review the medical records and neuroimaging studies of these patients. Patient assent and consent was obtained at the time of surgery for the use of imaging.

\section{Results}

\section{Overall Study Population}

Our series included 42 patients ( 28 boys and 14 girls) who had undergone a total of 51 operations. Patients were between 4 and 18 years old (median 12.3 years) at the time of their initial surgery. The most common pathological subtypes were craniopharyngioma $(n=16)$, followed by pituitary adenoma $(n=12)$, Rathke cleft cyst $(n=4)$, germinoma $(n=4)$, and chordoma $(n=2)$, with other smaller lesion subtypes $(n=4)$ (Fig. 2). The most common presenting symptoms were hormonal deficiencies $(70.6 \%)$, followed by visual change $(68.6 \%)$ and headache $(45 \%)$. On preoperative imaging, $62.7 \%$ of the lesions had suprasellar extension, and $63 \%$ of these lesions were approached with an attempt at GTR. The preoperative cavernous intercarotid distance ranged from 8.5 to $28.3 \mathrm{~mm}$ (median 18.1 


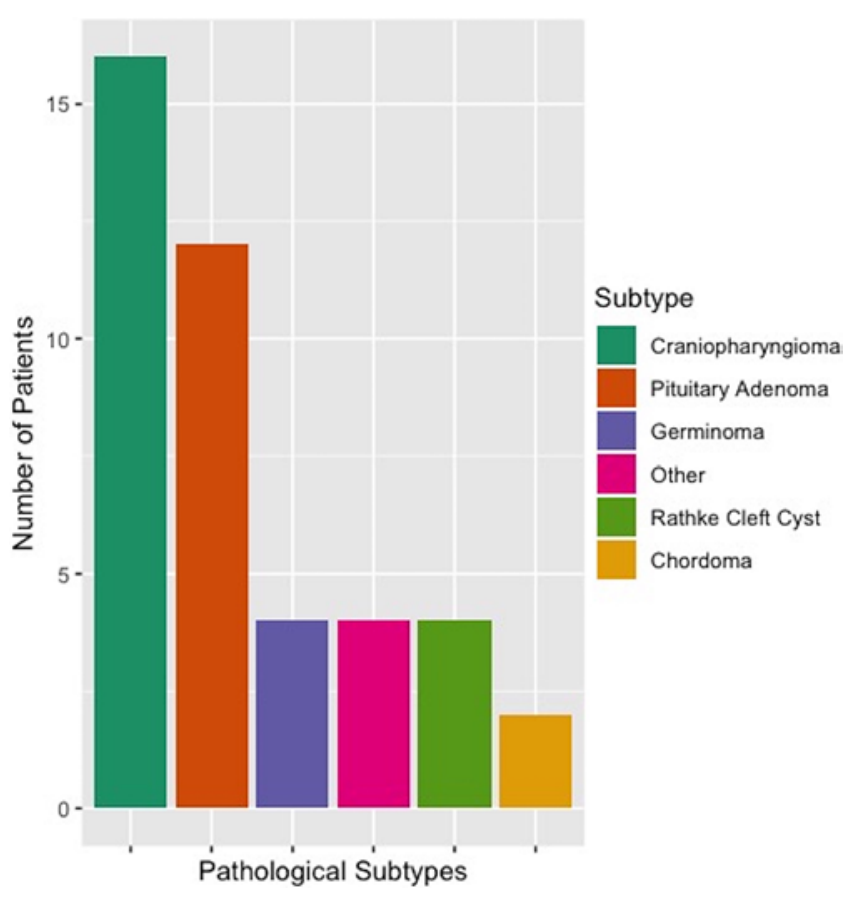

FIG. 2. Bar graph showing the pathological subtypes of lesions among patients included in the study. Figure is available in color online only.

$\mathrm{mm}$ ) (Table 1). The correlation between preoperative cavernous intercarotid distance and age can be appreciated in Fig. 3.

\section{Surgical Approach}

In most of the cases, neurosurgeons and otolaryngologists jointly performed the operations. Eight operations were performed by one neurosurgeon (M.S.B.E.) without otolaryngologists. The operative technique was similar across our different neurosurgeons for similar types of pathology. Most cases were GTRs (62.7\%), with fewer STRs (17.6\%), including cyst aspirations, and biopsies (15.6\%) (Fig. 4). The majority of GTRs were for lesions with suprasellar extension (63\%). Figure 5 shows intraoperative images of a GTR. Neuronavigation was used in all cases. Many of the operations were augmented by procedures to prevent CSF leakage such as placement of an intraoperative lumbar drain (47.1\%), nasoseptal flap (47.1\%), or fat graft $(37.3 \%)$. Reported blood loss ranged from 0 to 300 $\mathrm{ml}$ (median $50 \mathrm{ml}$ ). The median operative time was 235 minutes. Five patients had undergone prior transcranial surgery for either Ommaya reservoir placement or frontal cystic decompression; one patient had an Ommaya reservoir placed after resection (Table 1).

\section{Postoperative Course}

The majority of cases $(91.7 \%)$ resulted in clinical improvement over a median follow-up of 46 months (range 1-120 months). Assessment of meaningful clinical improvement was based on patient and family reports and the clinician's evaluation during postoperative follow-up visits. Some examples of reversal or alleviation of preop- erative symptoms consisted of resolution of headaches, improved peripheral vision in a patient with bitemporal hemianopia, and regained energy level in a fatigued patient with low cortisol level. Clinical follow-up was unavailable for 3 patients who moved out of state. In $27.5 \%$ of the cases, patients experienced postoperative complications (Table 1).

Most of the patients (76.2\%) required adjuvant therapy in the form of hormonal therapy $(69.0 \%)$, radiation therapy $(28.6 \%)$, or chemotherapy (16.7\%). Hormonal therapy was aimed at replacement $(n=21)$, suppression with cabergoline or bromocriptine $(n=4)$, or both $(n=3)$. Radiation therapy included external-beam LINAC-based therapy, with $(n=1)$ or without $(n=10)$ stereotactic radiosurgery using the CyberKnife, or brachytherapy $(n=1)$. Five patients did not have a repeat postoperative image to compare with the scan obtained immediately postoperatively. Five recurrences were reported after radiographically documented GTR (Table 2). Figure 6 demonstrates pre- and postoperative images obtained in a patient who underwent a successful GTR.

Detailed preoperative, intraoperative, and postoperative characteristics by each tumor type are as follows.

\section{Pituitary Adenomas}

There were 12 patients ranging in age from 7 to 18 years (median 11.8 years) who underwent 14 operations for pituitary adenoma. All adenomas were found to be secreting tumors, the majority of which were prolactinomas $(\mathrm{n}=7)$ with fewer adrenocorticotropic hormone-secreting $(\mathrm{n}=2)$, growth hormone-secreting $(\mathrm{n}=1)$, and mixedsecreting $(n=2)$ subtypes. Preoperatively, these patients all presented with symptoms related to pituitary hormone dysfunction. Patients with prolactinomas were offered surgical intervention after failed medical management with bromocriptine or cabergoline, marked by continued increase in prolactin levels or progressive visual loss.

Over $40 \%$ of the lesions had evidence of suprasellar extension. Gross-total resection was performed in $78.6 \%$ of the cases. Complications (14.3\%) included one case of a cavernous sinus tear that was promptly repaired and another of new hormonal deficit. The majority of patients (75\%) received adjuvant therapy with hormonal therapy and/or radiation therapy. Two patients underwent repeat surgery for recurrences, 4 and 5 years from the initial surgery (Table 2).

\section{Craniopharyngiomas}

A total of 22 operations were performed in 16 patients with craniopharyngiomas. Of note, during the same timeframe (2007-2016), 8 craniotomies were performed for resection of craniopharyngioma and 5 craniotomies for cyst aspiration/Ommaya reservoir placement in this population. Patients most commonly presented with visual changes ( $82 \%$ of cases), headache (62.5\% of cases), or hormonal deficiencies (55\% of cases). Visual changes included decreased visual acuity or visual field defects in 11 patients and proptosis in 1 patient. All patients with hormonal deficiencies exhibited panhypopituitarism, including growth failure and diabetes insipidus. Most of the 
TABLE 1. Cohort overview by tumor type

\begin{tabular}{|c|c|c|c|c|}
\hline & Overall $(n=42)$ & $\begin{array}{l}\text { Pituitary Adenoma } \\
\qquad(\mathrm{n}=12)\end{array}$ & $\begin{array}{l}\text { Craniopharyngioma } \\
\qquad(\mathrm{n}=16)\end{array}$ & Others $(n=14)$ \\
\hline Total no. of ops & 51 & 14 & 22 & 15 \\
\hline Median age, yrs & $12.3(4-18)$ & $16(7-18)$ & $11.8(5.9-16)$ & $11(4-18)$ \\
\hline Male sex & $28 / 42(66.7 \%)$ & $7 / 12(58.3 \%)$ & $11 / 16(68.8 \%)$ & $10 / 14(71.4 \%)$ \\
\hline \multicolumn{5}{|l|}{ Preop symptoms } \\
\hline Headache & $23 / 51(45 \%)$ & $7 / 14(50 \%)$ & $9 / 22(40.9 \%)$ & $7 / 15(46.7 \%)$ \\
\hline Visual change & $35 / 51(68.6 \%)$ & $7 / 14(50 \%)$ & $18 / 22(81.8 \%)$ & $10 / 15(66.7 \%)$ \\
\hline Other $\mathrm{CN}$ deficits & $3 / 51(5.98 \%)$ & $0 / 14(0 \%)$ & $1 / 22(4.5 \%)$ & $2 / 15(13.3 \%)$ \\
\hline Hormonal deficiency & $36 / 51(70.6 \%)$ & $14 / 14(100 \%)$ & $12 / 22(54.5 \%)$ & $10 / 15(66.7 \%)$ \\
\hline Hydrocephalus/papilledema & $6 / 51(11.8 \%)$ & $0 / 14(0 \%)$ & $6 / 22(27.3 \%)$ & $0(0 \%)$ \\
\hline Suprasellar extension & $32 / 51(62.7 \%)$ & $6 / 14(42.9 \%)$ & $20 / 22(90.9 \%)$ & $6 / 15(40 \%)$ \\
\hline Median greatest tumor dimension, $\mathrm{cm}$ & $2.5(0.3-6.2)$ & $1.6(0.3-4)$ & $3.7(1.6-4.7)$ & $1.9(0.3-6.2)$ \\
\hline Median intercarotid distance, $\mathrm{mm}$ & $18.1(8.5-28.3)$ & $18.8(14.2-24.8)$ & $16.9(11.4-28.3)$ & $18.1(8.5-26.4)$ \\
\hline \multicolumn{5}{|l|}{ Type of op } \\
\hline GTR & $32 / 48(62.7 \%)$ & $11 / 14(78.6 \%)$ & $16 / 22(72.7 \%)$ & $5 / 13(38.4 \%)$ \\
\hline STR/cyst aspiration & $9 / 48(17.6 \%)$ & $3 / 14(21.4 \%)$ & $5 / 22(22.7 \%)$ & $1 / 13(7.7 \%)$ \\
\hline Biopsy & $8 / 48(15.6 \%)$ & $0 / 14(0 \%)$ & $1 / 22(4.5 \%)$ & $7 / 13(53.8 \%)$ \\
\hline \multicolumn{5}{|l|}{ Additional procedures } \\
\hline Lumbar drain & $24 / 51(47.1 \%)$ & $4 / 14(28.6 \%)$ & $14 / 22(63.6 \%)$ & $6 / 15(40 \%)$ \\
\hline Septal flap & $24 / 51(47.1 \%)$ & $5 / 14(35.7 \%)$ & $9 / 22(40.9 \%)$ & $5 / 15(33.3 \%)$ \\
\hline Fat graft & 19/51 (37.3\%) & $7 / 14(50 \%)$ & $14 / 22(63.6 \%)$ & $3 / 15(20 \%)$ \\
\hline Median intraop blood loss, $\mathrm{ml}$ & $50(0-300)$ & $75(50-150)$ & $87.5(0-300)$ & $50(10-125)$ \\
\hline No. of transfusions & $2 / 51(3.9 \%)$ & $0 / 14(0 \%)$ & $2 / 22(9.1 \%)$ & $0 / 15(0 \%)$ \\
\hline Median op time, mins & $235(65-439)$ & $436(240-436)$ & $215(65-439)$ & $276(171-405)$ \\
\hline Median length of stay, days & $5(1-61)$ & $4.5(2-8)$ & $7.5(1-37)$ & $4(2-61)$ \\
\hline Complications, any & $14 / 51(27.5 \%)$ & $2 / 14(14.3 \%)$ & $9 / 22(40.9 \%)$ & $3 / 15(20 \%)$ \\
\hline CSF leak & $3 / 51(5.9 \%)$ & $0 / 14(0 \%)$ & $3 / 22(13.6 \%)$ & $0 / 15(0 \%)$ \\
\hline New CN deficits & $3 / 51(5.9 \%)$ & $0 / 14(0 \%)$ & $2 / 22(9.1 \%)$ & $1 / 15(6.7 \%)$ \\
\hline New hormonal deficits & $8 / 51(15.7 \%)$ & $1 / 14(7.1 \%)$ & $7 / 22(31.8 \%)$ & $0 / 15(0 \%)$ \\
\hline Hemorrhage & $3 / 51(5.9 \%)$ & $0 / 14(0 \%)$ & $2 / 22(9.1 \%)$ & $1 / 15(6.7 \%)$ \\
\hline Infection & $2 / 51(3.9 \%)$ & $0 / 14(0 \%)$ & $1 / 22(4.5 \%)$ & $1 / 15(6.7 \%)$ \\
\hline Graft migration & $2 / 51(3.9 \%)$ & $0 / 14(0 \%)$ & $2 / 22(9.1 \%)$ & $0 / 15(0 \%)$ \\
\hline Death & $1 / 51(2.0 \%)$ & $0 / 14(0 \%)$ & $1 / 22(4.5 \%)$ & $0 / 15(0 \%)$ \\
\hline Median follow-up time, mos & $46(1-120)$ & $18.5(1-64)$ & $57(21-114)$ & $46(22-120)$ \\
\hline No. of recurrences & $5 / 32(15.6 \%)$ & $2 / 11(18.2 \%)$ & $3 / 16(18.8 \%)$ & $0 / 5(0 \%)$ \\
\hline No. of reops & $9 / 51(17.6 \%)$ & $2 / 14(14.3 \%)$ & $6 / 22(27.3 \%)$ & $1 / 15(6.7 \%)$ \\
\hline Adjuvant therapy, any & $32 / 42(76.2 \%)$ & $9 / 12(75 \%)$ & $14 / 16(87.5 \%)$ & $9 / 14(64.3 \%)$ \\
\hline Hormonal therapy & $29 / 42(69.0 \%)$ & $9 / 12(75 \%)$ & $12 / 16(75 \%)$ & $8 / 14(57.1 \%)$ \\
\hline Radiation therapy & $12 / 42(28.6 \%)$ & $2 / 12(16.7 \%)$ & $4 / 16(25 \%)$ & $6 / 14(42.9 \%)$ \\
\hline Chemotherapy & $7 / 42(16.7 \%)$ & $0 / 12(0 \%)$ & $1 / 16(6.3 \%)$ & $6 / 14(42.9 \%)$ \\
\hline
\end{tabular}

$\mathrm{CN}=$ cranial nerve.

Median values are presented as the median (range).

cases were attempted as GTRs (72.7\%). The average blood loss was $109.4 \mathrm{ml}$, and 2 patients required blood transfusion. Six reoperations were performed for a recurrence of craniopharyngioma $(\mathrm{n}=1)$ and a residual lesion after STR $(\mathrm{n}=1)$, and 4 additional operations were performed in 1 patient with cyst reaccumulation despite multiple transnasal aspirations and prior STR (Tables 1-3).
Postoperative complications were observed in $40.9 \%$ of cases. All 3 postoperative CSF leaks (13.6\%) involved lesions with suprasellar extension. There was 1 case of bacterial meningitis successfully treated with antibiotics. New hormonal deficits were observed (31.8\%), most often in the form of diabetes insipidus, syndrome of inappropriate salt wasting, and panhypopituitarism. Three patients 


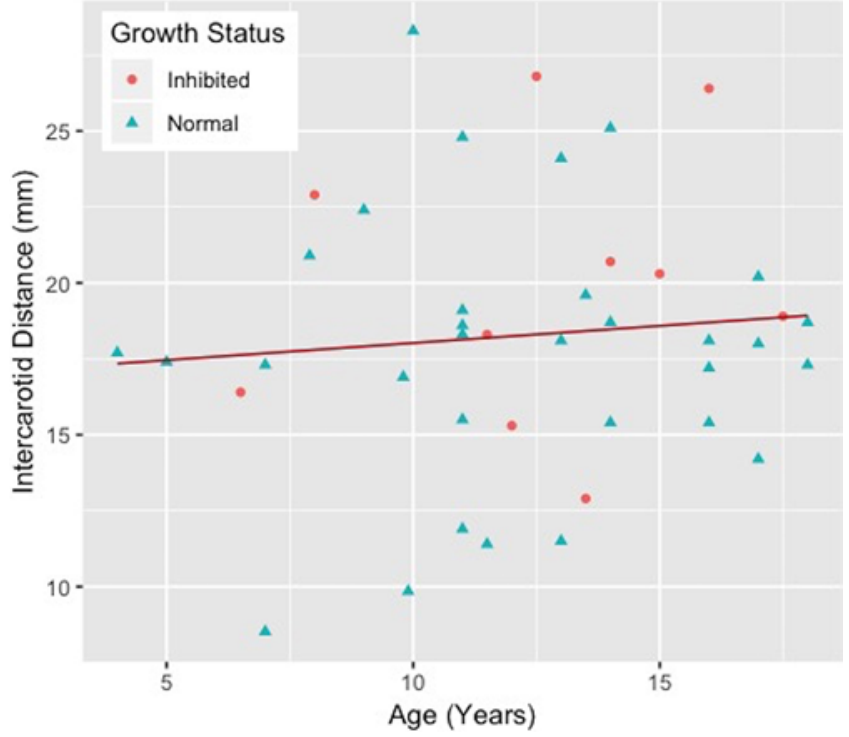

FIG. 3. Scatterplot of age and cavernous intercarotid distance at the time of the first procedure. The red line represents a linear regression model showing the relationship between the two variables. Figure is available in color online only.

with new-onset weight gain attributable to hypothalamic obesity were included in this count, but not the patients with positive weight gain from underweight to normal weight range $(n=2)$, preexisting obesity $(n=5)$, and transient weight gain secondary to steroid use $(\mathrm{n}=1)$.

One case was aborted due to excessive bone bleeding, later requiring a subfrontal craniotomy for resection. Two patients had intracranial migration of fat grafts, both of whom demonstrated acute postoperative worsening of their vision. In both instances, intracranial hypotension due to the use of a lumbar drain was felt to be causative. During the reoperation to remove both the packing material and fat graft, the fat graft was found to be compressing the optic nerve in one case and the optic chiasm in the other. Both patients saw significant improvement in their visual symptoms after the revision surgeries.

One patient died in the immediate postoperative period due to disseminated intravascular coagulation. Intraoperatively, the patient had approximately $300 \mathrm{ml}$ of blood loss (estimated total blood volume from weight: $18.1 \mathrm{~kg} \times 70$ $\mathrm{ml} / \mathrm{kg}=1260 \mathrm{ml}$ ) from the surgical site, but hemostasis was achieved with Gelfoam. The patient was hemodynamically stabilized with a blood transfusion. CT scans obtained before transferring the patient to the ICU showed no significant intracranial hemorrhage. On arrival to the ICU, the patient started to bleed from both nares and subsequently developed coagulopathy. Bedside CT scanning revealed intraventricular and subarachnoid hemorrhages. Despite aggressive management, the patient's condition further deteriorated to brain death.

\section{Other Skull Base Lesions}

Other less common skull base lesions included Rathke cleft cysts $(n=4)$, germinomas $(n=4)$, chordomas $(n=2)$, Ewing's sarcoma $(\mathrm{n}=1)$, and nongerminomatous germ cell

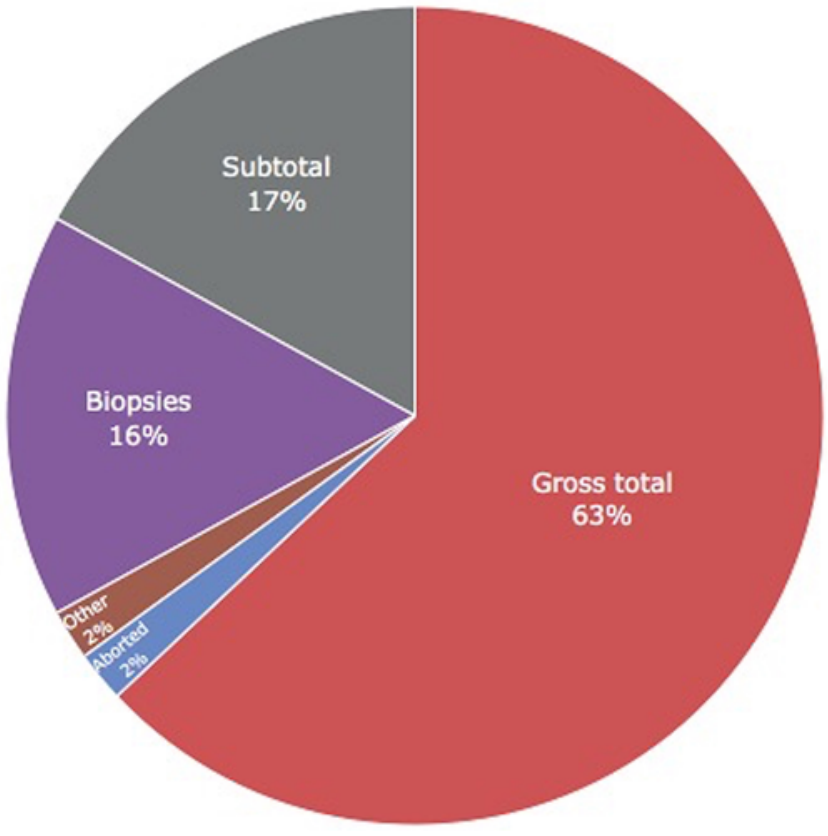

FIG. 4. Pie chart showing the types of surgical procedures performed for patients included in the study. Figure is available in color online only.

tumor $(\mathrm{n}=1)$. One patient had a nondiagnostic pituitary stalk biopsy that demonstrated only lymphocytic infiltration (who required a repeat biopsy to rule out neoplasm after the initial sample was deemed insufficient for definitive diagnosis), and another patient with fibrous dysplasia underwent transnasal endoscopic surgery for optic nerve decompression. Detailed clinical information of this heterogeneous group of patients is available in Tables 1 and 3 .
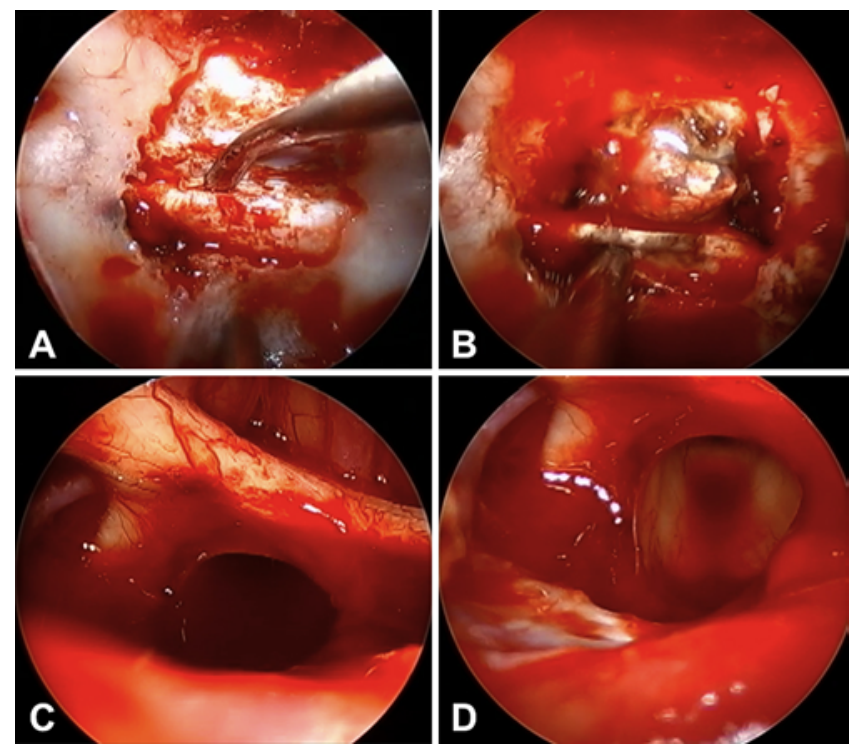

FIG. 5. Intraoperative endoscopic view demonstrating opening of the dura (A), tumor visualization (B), the optic nerve after tumor removal (C), and the third ventricle after tumor removal (D). Figure is available in color online only. 


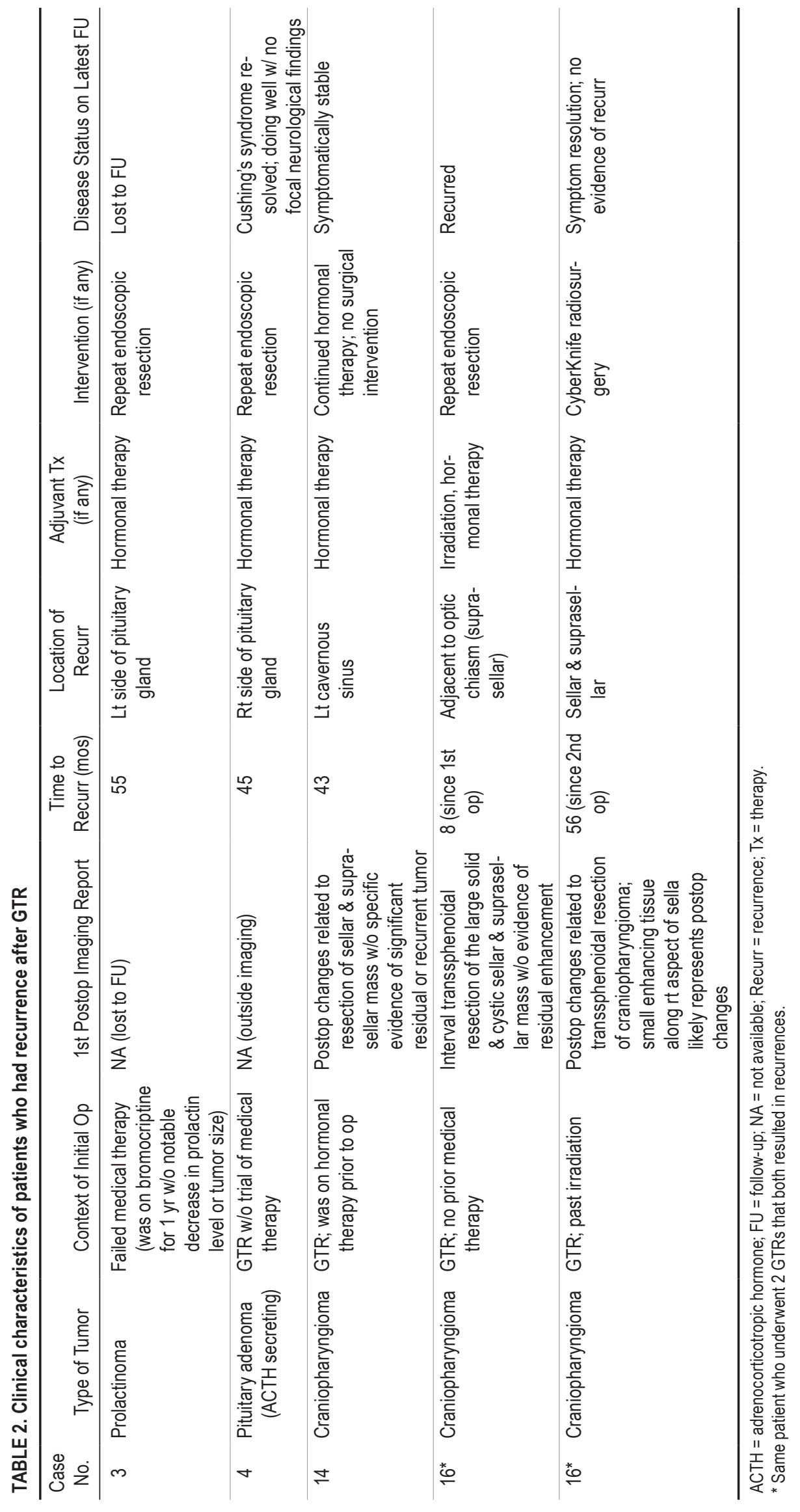



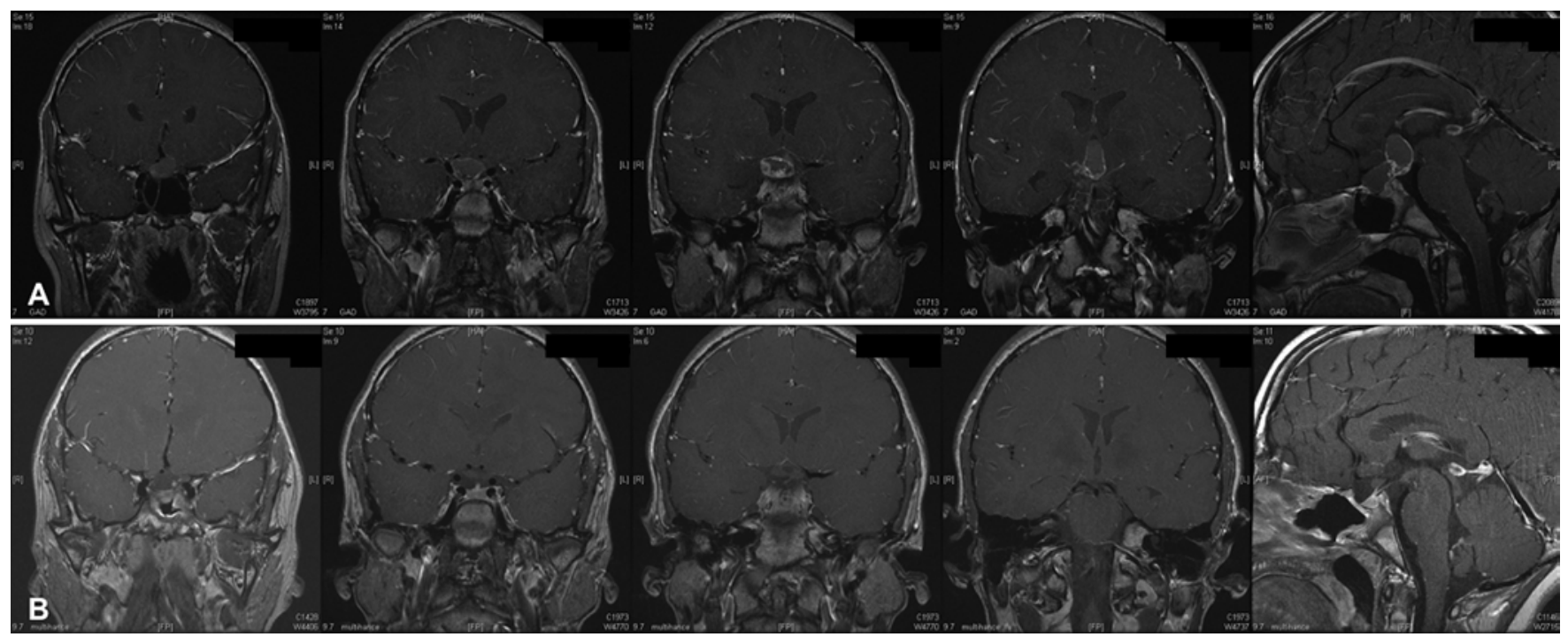

FIG. 6. Preoperative (A) and postoperative (B) postcontrast MR images obtained in an 11-year-old patient with a craniopharyngioma.

\section{Discussion}

Transnasal endoscopic approaches in children have mostly been reported as part of larger adult-inclusive series $^{5,10,12,23}$ or as case reports, ${ }^{16,18,32,33,36}$ but they have increasingly been described in the resection of pediatric skull base lesions. . $^{2,46,9,17,30,34,40,41}$ Our pediatric series presents a tertiary care center's experience of implementing this surgical approach for a diverse group of sellar and suprasellar pathologies (a total of 9 different indications). Previous reports of a similar nature have been published but were either smaller in sample size $e^{2,4,11,17,34}$ or conducted in a different country. ${ }^{12,24,30,38,40,41}$ Larger case series from the US have been published but were all from the same institution. ${ }^{6,935}$ Among the sizable pediatric case series from American institutions, we present the longest median follow-up time of 4 years. ${ }^{2,4,6,34}$

\section{Pituitary Adenomas}

In their series of 56 pediatric patients with pituitary adenomas, Zhan et al. reported a high rate of GTR (87.5\%). ${ }^{41}$ These authors additionally described a smaller subset of 11 adolescent patients with similar outcomes. ${ }^{40}$ Their patients were between 10 and 18 years old, with the majority (91\%) older than 15 years. ${ }^{41}$ Therefore, many of their patients had skull base anatomy closer to adult size. ${ }^{40}$ These patients primarily presented with visual deficits and symptoms related to hormonal deficits, with clinical improvement immediately after surgery..$^{40,41}$ In our study, we saw similarly high rates of overall clinical improvement (92\%). Given what they deem to be comparable rates of safety and efficacy with the adult population, these authors advocate for the use of the endonasal endoscopic approach for pediatric pituitary adenomas.

\section{Craniopharyngiomas}

A number of series have also described transsphenoidal, but not purely transnasal endoscopic, resection of craniopharyngiomas in children with good outcomes. ${ }^{1,22,38}$
These series primarily utilized the operating microscope for visualization. In their series of 22 patients, Jane et al. included 2 children who underwent a purely endoscopic endonasal resection of their craniopharyngiomas, which they acknowledged has since become the predominant surgical technique. ${ }^{15}$ Their rate of GTR (68\%) was similar to ours (62.7\%) but had a higher rate of new hormonal deficits $(67 \%$ cases of panhypopituitarism, $56 \%$ cases of new diabetes insipidus).

\section{Other Skull Base Lesions}

The endoscopic transnasal approach has also been described in the setting of other skull base lesions. ${ }^{4,6,34}$ Kassam et al. reported their institutional experience of expanded endoscopic endonasal approaches for optic nerve decompression and CSF leak repair in addition to tumor resection. ${ }^{17}$ In this series, 2 of 25 patients (8\%) had postoperative CSF leakage, although increasing use of a nasoseptal flap was thought to reduce this risk. ${ }^{17}$ They later reported using a nasoseptal flap in $41.4 \%$ of cases, with $48 \%$ of patients having intraoperative and $10.5 \%$ postoperative CSF leakage in their full series of 133 pediatric patients undergoing the same procedure. ${ }^{6}$

Based on 33 children who underwent endoscopic endonasal approaches for neoplasms, congenital malformations, and skull base defects, Banu et al. reported a GTR rate $(75 \%)$ comparable to ours $(62.5 \%) .{ }^{4}$ Interestingly, they found that the patient's age did not significantly impact the extent of resection or overall clinical outcome. ${ }^{4}$ In their series of 97 adult and 3 adolescent patients, de Divitiis et al. suggested that the endoscopic endonasal approach allows for safe resection of a diverse array of pathologies. ${ }^{8}$ While most of our patients had pituitary adenomas and craniopharyngiomas, we also included a few patients with other skull base pathologies (e.g., Ewing's sarcoma, optic nerve compression from fibrous dysplasia). Some authors might argue that a transnasal approach should be limited to tumors contained within the sella or below the diaphragma sellae. ${ }^{1,31}$ It is our experience in children that the 
TABLE 3. List of individual patients, by tumor type

\begin{tabular}{|c|c|c|c|c|c|c|}
\hline Case No. & $\begin{array}{l}\text { Age (yrs), } \\
\text { Sex }\end{array}$ & Subtype & Preop Signs/Symptoms & $\begin{array}{l}\text { Suprasellar } \\
\text { Extension }\end{array}$ & $\begin{array}{c}\text { Tumor } \\
\text { Dimension }(\mathrm{cm})\end{array}$ & Op Type \\
\hline \multicolumn{7}{|c|}{ Pituitary adenoma $(n=12)^{*}$} \\
\hline 1 & $11, M$ & $\begin{array}{l}\text { Pituitary adenoma (mixed } \\
\text { prolactin, GH secret- } \\
\text { ing) }\end{array}$ & $\begin{array}{l}\text { HAs, bitemp hemianopia, DI, elevated growth } \\
\text { hormone \& prolactin, hypothyroidism }\end{array}$ & Yes & 3.6 & GTR \\
\hline 2 & $17, \mathrm{~F}$ & $\begin{array}{l}\text { Pituitary adenoma (mixed } \\
\text { prolactin, GH secret- } \\
\text { ing) }\end{array}$ & Acromegaly & No & 1.1 & GTR \\
\hline \multirow[t]{2}{*}{3} & $17, \mathrm{~F}$ & \multirow[t]{2}{*}{ Prolactinoma } & \multirow{2}{*}{$\begin{array}{l}\text { HAs, blurry vision, fatigue, weight gain, elevated } \\
\text { prolactin/galactorrhea, amenorrhea, temp } \\
\text { dysregulation, frequent urination }\end{array}$} & Yes & 1.7 & GTR \\
\hline & 22 & & & No & 1.4 & GTR \\
\hline \multirow[t]{2}{*}{4} & $17.5, \mathrm{M}$ & \multirow{2}{*}{$\begin{array}{l}\text { Pituitary adenoma (ACTH } \\
\text { secreting) }\end{array}$} & \multirow[t]{2}{*}{ Weight gain, acne, fatigue, increased cortisol } & No & NA & GTR \\
\hline & 21 & & & No & NA & GTR \\
\hline 5 & $17, \mathrm{~F}$ & Prolactinoma & HAs, fatigue, amenorrhea, galactorrhea & No & 0.8 & GTR \\
\hline 6 & $7, M$ & $\begin{array}{l}\text { Pituitary adenoma (GH } \\
\text { secreting) }\end{array}$ & Eye deviation, ptosis, acromegaly & No & 0.9 & GTR \\
\hline 7 & $16, \mathrm{M}$ & $\begin{array}{l}\text { Pituitary adenoma (ACTH } \\
\text { secreting) }\end{array}$ & Cushing's disease & No & 0.3 & GTR \\
\hline 8 & $18, F$ & Prolactinoma & Visual field deficit, elevated prolactin & No & 1.5 & GTR \\
\hline 9 & $7.9, \mathrm{~F}$ & Prolactinoma & $\begin{array}{l}\text { HAs, visual loss, bitemp hemianopia, weight gain, } \\
\text { amenorrhea, elevated prolactin, DI }\end{array}$ & Yes & 2.6 & STR \\
\hline 10 & $13.5, \mathrm{M}$ & Prolactinoma & $\begin{array}{l}\text { HAs, bitemp hemianopia, optic atrophy, elevated } \\
\text { prolactin, DI }\end{array}$ & Yes & 4 & STR \\
\hline 11 & $16, \mathrm{M}$ & Prolactinoma & $\begin{array}{l}\text { HAs, visual loss, bitemp hemianopia, elevated } \\
\text { prolactin }\end{array}$ & Yes & 2.1 & GTR \\
\hline 12 & $13, M$ & Prolactinoma & Visual loss, elevated prolactin & Yes & 2.7 & STR \\
\hline \multicolumn{7}{|c|}{ Craniopharyngioma ( $n=16$ ) } \\
\hline 13 & $14, \mathrm{~F}$ & & HAs, vision loss & Yes & 2.4 & GTR \\
\hline 14 & $12.5, \mathrm{~F}$ & & HAs, bilat hemianopia & Yes & 3.5 & GTR \\
\hline 15 & $13, \mathrm{~F}$ & & $\begin{array}{l}\text { HAs, blurry vision, papilledema, obstructive } \\
\text { hydrocephalus }\end{array}$ & Yes & 3.9 & GTR \\
\hline \multirow[t]{2}{*}{16} & $15, \mathrm{M}$ & & \multirow{2}{*}{$\begin{array}{l}\text { Rt eye vision loss, visual field cuts, poor appetite, } \\
\text { constipation, dry skin }\end{array}$} & Yes & 4 & GTR \\
\hline & 17 & & & Yes & 1.7 & GTR \\
\hline \multirow[t]{2}{*}{17} & $9, M$ & & \multirow{2}{*}{$\begin{array}{l}\text { HAs, visual field deficit, proptosis, congestion, } \\
\text { rhinorrhea, airway obstruction }\end{array}$} & No & 1.6 & STR \\
\hline & 10 & & & No & 2.3 & GTR \\
\hline 18 & $8, M$ & & Bitemp hemianopia, panhypopituitarism & Yes & 4 & GTR \\
\hline 19 & $11, \mathrm{~F}$ & & HAs, papilledema & Yes & 2.1 & GTR \\
\hline 20 & $14, \mathrm{M}$ & & Visual loss, bitemp hemianopia & Yes & 3.7 & GTR \\
\hline 21 & $12, \mathrm{~F}$ & & Visual problems, growth failure, fatigue & Yes & 3.6 & $\mathrm{STR} \times 4, \mathrm{GTR}$ \\
\hline 22 & $6.5, \mathrm{M}$ & & $\begin{array}{l}\text { Visual field deficit, panhypopituitarism, hydro- } \\
\text { cephalus, vomiting }\end{array}$ & Yes & 4.4 & GTR \\
\hline 23 & $9.8, \mathrm{M}$ & & HAs, weight loss, N/V, papilledema & Yes & 3.7 & GTR \\
\hline 24 & $10, M$ & & HAs & Yes & 4.7 & Biopsy \\
\hline 25 & 13.5, M & & HAs, growth retardation, hydrocephalus, vomiting & Yes & 4.5 & GTR \\
\hline 26 & $11.5, \mathrm{M}$ & & HAs, blurry vision & Yes & 4.3 & GTR \\
\hline 27 & $14, \mathrm{M}$ & & Visual loss, panhypopituitarism & Yes & 1.8 & GTR \\
\hline 28 & $5.9, \mathrm{M}$ & & $\begin{array}{l}\text { HAs, optic nerve compression, panhypopituita- } \\
\text { rism, hydrocephalus, N/V }\end{array}$ & Yes & 4.4 & GTR \\
\hline
\end{tabular}


» CONTINUED FROM PAGE 253

TABLE 3. List of individual patients, by tumor type

\begin{tabular}{|c|c|c|c|c|c|c|}
\hline Case No. & $\begin{array}{l}\text { Age (yrs) } \\
\text { Sex }\end{array}$ & Subtype & Preop Signs/Symptoms & $\begin{array}{l}\text { Suprasellar } \\
\text { Extension }\end{array}$ & $\begin{array}{c}\text { Tumor } \\
\text { Dimension }(\mathrm{cm})\end{array}$ & Op Type \\
\hline \multicolumn{7}{|c|}{$\operatorname{RCC}(n=4)$} \\
\hline 29 & $14, F$ & & HAs, impaired vision & No & 1.1 & GTR \\
\hline 30 & $5, M$ & & $\begin{array}{l}\text { HAs, vision loss, visual field deficit, panhypopitu- } \\
\text { itarism }\end{array}$ & Yes & 2.7 & STR \\
\hline 31 & $18, F$ & & $\begin{array}{l}\text { HAs, blurry vision, bitemp hemianopia, pituitary } \\
\text { apoplexy, dizziness }\end{array}$ & No & 1 & Biopsy \\
\hline 32 & $11, \mathrm{M}$ & & $\begin{array}{l}\text { Visual loss, bitemp hemianopia, hormone defi- } \\
\text { ciencies }\end{array}$ & Yes & 2.4 & GTR \\
\hline \multicolumn{7}{|c|}{ Germinoma $(n=4)$} \\
\hline 33 & $11, \mathrm{~F}$ & & Fatigue, DI & No & $\begin{array}{l}\text { NA ("bright } \\
\text { spot") }\end{array}$ & Biopsy \\
\hline 34 & $16, \mathrm{M}$ & & Vision loss, panhypopituitarism & Yes & 2.5 & GTR \\
\hline 35 & $7, \mathrm{~F}$ & & $\mathrm{DI}$ & Yes & 0.55 & Biopsy \\
\hline 36 & $11.5, \mathrm{M}$ & & Panhypopituitarism & Yes & NA & Biopsy \\
\hline \multicolumn{7}{|c|}{ Chordoma $(n=2)$} \\
\hline 37 & $11, M$ & & HAs, diplopia, CN VI palsy & No & 0.3 & GTR \\
\hline 38 & $11, \mathrm{M}$ & & HAs, double vision, CN VI palsy & No & 3.2 & GTR \\
\hline \multicolumn{7}{|c|}{ Other $(n=4)$} \\
\hline 39 & $10, M$ & Lymphocytic cells & DI, elevated growth hormone & No & $\begin{array}{l}\text { NA (enhancing } \\
\text { stalk) }\end{array}$ & Biopsy \\
\hline 40 & $4, M$ & Ewing's sarcoma & $\begin{array}{l}\text { HAs, proptosis, poor appetite, drowsiness, nasal } \\
\text { discharge }\end{array}$ & No & 6.2 & Biopsy \\
\hline 41 & $16, M$ & $\begin{array}{l}\text { Nongerminomatous germ } \\
\text { cell tumor }\end{array}$ & $\begin{array}{l}\text { HAs, visual loss, photophobia, N/V panhypopitu- } \\
\text { itarism, elevated beta-HCG \& AFP }\end{array}$ & Yes & 1.4 & $\begin{array}{l}\text { Aborted due to } \\
\text { bony bleed- } \\
\text { ing }\end{array}$ \\
\hline 42 & $13, M$ & $\begin{array}{l}\text { Optic canal decompres- } \\
\text { sion }\end{array}$ & Progressive blindness & NA & NA & Other \\
\hline
\end{tabular}

AFP = alpha-fetoprotein; bitemp = bitemporal; $\mathrm{DI}=$ diabetes insipidus; $\mathrm{GH}=$ growth hormone; $\mathrm{HA}$ = headache; $\mathrm{HCG}=$ human chorionic gonadotropin; $\mathrm{N} / \mathrm{V}=$ nauseal vomiting; RCC $=$ Rathke cleft cyst.

endoscopic transnasal approach can be used for GTR of intrasellar as well as suprasellar lesions while minimizing postoperative complications. Compared with open resection, endoscopic approaches have shorter hospital stays, fewer blood transfusions, and lower postoperative pain scores..$^{30}$ Our median blood loss was $50 \mathrm{ml}$, and the length of stay was 5 days.

\section{Special Considerations in the Pediatric Population}

\section{Anatomical Limitations}

In children, the anatomical limitations of endoscopic endonasal approaches are dependent on age-related parameters of the face and skull base. ${ }^{4}$ While intracranial measurements usually reach $95 \%$ of adult size at 10 years of age, facial measurements only appear to be at $85 \%$ of adult size. Skull base pathology itself can disrupt normal anatomical dimensions that subsequently hinder endonasal access. ${ }^{4}$ The intercarotid distance at the level of the cavernous sinus is significantly smaller in children, but inferiorly at the superior clivus, it does not appear to vary significantly with age., 4,29,37 The ability to perform a GTR is related to the intercarotid distance and the lateral extent of the tumor into the cavernous sinus or middle cranial fossa. ${ }^{29}$ Wider intercarotid distance and shorter nare-dens working distance are associated with better resection outcomes., ${ }^{439}$ In our study, the cavernous intercarotid distance of the overall study cohort, whose mean age was in the early teens, was comparable to the length reported in adults. ${ }^{26}$ The lack of significant difference in cavernous intercarotid distance between adults and children older than 9 years has been previously reported. ${ }^{37}$ However, in our experience with children younger than 10 years, the approach was often limited by the narrow approach afforded into the sella. In addition, 11 children demonstrated growth failure, which may have resulted in smaller skull base anatomical structures for age, further complicating surgical access. As expected, intercarotid distance was positively correlated with age (Fig. 3) and inversely related to operative times. As the exact operative times were often unavailable for many patients, a formal regression analysis was deferred. 
Sellar pneumatization, or lack thereof, is another consideration unique to the pediatric population. Children often do not have a pneumatized sella, a process which begins around the age of 3 years and continues into the teenage years. ${ }^{20,37}$ In children with growth hormone deficiency, the sella is delayed in pneumatization. Children with a nonpneumatized sphenoid required drilling out of the sphenoid bone to gain access to the tumor. Furthermore, the lack of landmarks in the absence of sellar pneumatization such as the optico-carotid recess makes localization challenging. ${ }^{20}$ In these cases, beginning with a pediatric endoscope $(2.7 \mathrm{~mm})$ and transitioning after the initial exposure to an adult-sized endoscope $(4 \mathrm{~mm})$ can facilitate visualization. ${ }^{20}$ Smaller children may therefore require a sublabial approach in order to have enough working space for instrument placement and for greater intra- and suprasellar exposure. $7,15,19,28$

\section{Surgical Instruments}

At our institution, a $45^{\circ}$ angled endoscope was used for lateral and superior views of the tumor. Once in the intracranial space, we used a variety of endoscopes with angles ranging from $0^{\circ}$ to $45^{\circ}$ for adequate visualization depending on the suprasellar extent of the lesion. Transnasal microscopic instruments were used for dissection and resection. The NICO Myriad device (NICO Corp.), an aspiration device designed for the neuroendoscope, ${ }^{27}$ was not utilized based on surgeon preference and experience with adult cases at our institution.

The manipulation of operative instruments poses unique challenges in children. Instrumental limitations of this approach have been noted in the adult literature as well. For instance, intranasal drills generate bone dust but may lack built-in irrigation and suction functionality, hindering the achievement of ideal visualization. ${ }^{25}$ Even when performed correctly, irrigation results in transient yet complete obliteration of the surgical field in the narrow sinonasal corridor. Such challenges are only magnified in the pediatric population, especially in the absence of microscopic instruments designed solely for children to accommodate for their diminutive anatomical structures. ${ }^{24}$ Passage of multiple instruments within the confines of the tight operative field requires dynamic movement and careful positioning. In our experience, the ability to simultaneously place 3 instruments (endoscope, drill, and suction or bipolar electrocautery) was especially limited in children younger than 8 years or in those with a nonpneumatized sella. This difficulty persisted despite the use of pistolgrip bipolar forceps, suggesting that the development of specialized instrumentation for young children would enhance our ability to resect complex suprasellar lesions. Different pathologies may present additional challenges for instrument manipulation, such as a small bony opening that is further decreased by hyperostosis of the sphenoid bone due to pituitary tumor or tissue with increased vascularity in the context of Cushing disease that requires meticulous hemostasis.

\section{Structural Preservation}

Compared with craniotomy, an endoscopic endonasal approach can help limit brain retraction and prevent po- tential neurocognitive effects in children. ${ }^{17}$ An endoscope may circumvent facial retraction injury from the speculum used during a traditional craniofacial approach. ${ }^{17} \mathrm{Ad}-$ ditionally, the endoscopic approach allows dentition and facial growth plates to be preserved, which are important advantages in the pediatric population. ${ }^{17,28}$ Studies from the otolaryngology literature indicate that children who have undergone endoscopic sinus surgery do not differ later in life regarding development of facial anatomical dimensions. ${ }^{20}$

\section{Surgical Approach and Adjunctive Procedures}

Literature on pediatric skull base lesions suggests that tumor consistency plays an important role in deciding whether a GTR is feasible and should be attempted.,29 Fibrous tumors may be more difficult to resect using a transnasal approach..$^{29}$ Some authors have argued that suprasellar calcifications in craniopharyngiomas warrant a transcranial approach. ${ }^{1}$ Firm or adherent suprasellar tumors or reoperations pose a higher risk of damaging the optic chiasm, carotid arteries, or other surrounding brain structures as well as a greater risk of bleeding. ${ }^{29}$

In addition to the main procedure, placement of nasoseptal flaps, fat grafts, and lumbar drains may be considered. In children younger than 10 years, a nasoseptal flap may not be of sufficient size to cover a large skull base defect. ${ }^{20}$ At our institution, packing of the sella with fat was used initially but was later discontinued, as this was no longer deemed necessary to achieve an adequate barrier to CSF leak. The use of a nasoseptal mucosal flap and packing of the sella with Gelfoam was adequate to prevent a CSF leak. A lumbar drain was placed in the operating room for CSF diversion to lower intracranial pressure when a higher chance of CSF leakage was expected, such as with tumors with significant supra- and parasellar extension. In fact, we observed postoperative CSF leakage only in craniopharyngiomas with suprasellar and/or parasellar extension, which necessitated intraoperatively entering the subarachnoid space, and not in intrasellar lesions. Our practice has evolved from open lumbar CSF drainage at the height of the foramen magnum to a controlled drainage of only $10 \mathrm{ml}$ per hour to minimize the risk of postoperative CSF leakage when intraoperative CSF was observed.

\section{Operative Environment and Training}

Endoscopic neurosurgery represents an important collaboration between otolaryngology and neurosurgery. Hardy famously adopted many of the tools used by otolaryngologists to resect not only pituitary tumors but also other skull base lesions. ${ }^{13}$ Increased comfort level with extended endoscopic endonasal approaches in the adult population has led to their wider application in children. ${ }^{20}$ Tools such as neuronavigation, intraoperative Doppler, and neuromonitoring can facilitate this approach. ${ }^{4,28}$ Intraoperative neuromonitoring is effective for detecting cranial nerve dysfunction during tumor dissection and can help mitigate damage to surrounding structures, and this technique is especially valuable during staged procedures and reoperations. ${ }^{9}$ There is a distinct learning curve associated with transnasal endoscopic surgeries that must also be 
overcome for complex surgeries in the pediatric population. $^{21}$

\section{Study Limitations}

We report only our own institutional experience, and, as with any surgical approach, there exists a distinct learning curve. However, the collaborative relationship between pediatric neurosurgeons and otolaryngologists has allowed our team to become experienced with this approach, and the evolution in our practice over time (e.g., discontinuation of fat grafts due to complications) reflects the process of gathering institutional knowledge. Long-term clinical follow-up was possible for the majority of patients, but as patients move into adulthood, availability of clinical records was limited by whether they were followed by an adult neurosurgeon at our institution. Despite the lack of uniformly obtainable data for all patients, the median follow-up time of our study cohort was 46 months, which is longer than that in previously published pediatric case series on transnasal endoscopic approaches in the US. Multiple pathologies were discussed in this case series, as might be expected in the pediatric population, but the variety of conditions treated by this surgical approach suggests its applicability to many different pediatric diseases. Given the rare incidence of many pediatric skull base lesions, only a few case series on this topic have focused on a single pathological condition.

\section{Conclusions}

This single-institution case series suggests that transnasal endoscopic approaches have utility for diagnosing and treating pediatric skull base lesions with a high likelihood of symptomatic relief. In particular, for prolactinomas, resection can be considered when medical therapy has failed or is not well tolerated. For craniopharyngiomas, resection can remove or debulk selected complex tumors, obviating either postoperative irradiation or chemotherapy. Favorable surgical outcomes require careful patient selection and an experienced team of surgeons. Further development in imaging, simulation techniques, and instrumentation will allow for careful preoperative planning and improved resection via minimally invasive exposure, thereby expanding the current use of this microsurgical approach.

\section{References}

1. Abe T, Lüdecke DK: Transnasal surgery for infradiaphragmatic craniopharyngiomas in pediatric patients. Neurosurgery 44:957-966, 1999

2. Alalade AF, Ogando-Rivas E, Boatey J, Souweidane MM, Anand VK, Greenfield JP, et al: Suprasellar and recurrent pediatric craniopharyngiomas: expanding indications for the extended endoscopic transsphenoidal approach. J Neurosurg Pediatr 21:72-80, 2018

3. Apuzzo ML, Heifetz MD, Weiss MH, Kurze T: Neurosurgical endoscopy using the side-viewing telescope. J Neurosurg 46:398-400, 1977

4. Banu MA, Rathman A, Patel KS, Souweidane MM, Anand VK, Greenfield JP, et al: Corridor-based endonasal endoscopic surgery for pediatric skull base pathology with detailed radioanatomic measurements. Neurosurgery 10 (Suppl 2):273-293, 2014
5. Ceylan S, Koc K, Anik I: Extended endoscopic approaches for midline skull-base lesions. Neurosurg Rev 32:309-319, 2009

6. Chivukula S, Koutourousiou M, Snyderman CH, FernandezMiranda JC, Gardner PA, Tyler-Kabara EC: Endoscopic endonasal skull base surgery in the pediatric population. J Neurosurg Pediatr 11:227-241, 2013

7. Das K, Spencer W, Nwagwu CI, Schaeffer S, Wenk E, Weiss $\mathrm{MH}$, et al: Approaches to the sellar and parasellar region: anatomic comparison of endonasal-transsphenoidal, sublabial-transsphenoidal, and transethmoidal approaches. Neurol Res 23:51-54, 2001

8. de Divitiis E, Cappabianca P, Gangemi M, Cavallo LM: The role of the endoscopic transsphenoidal approach in pediatric neurosurgery. Childs Nerv Syst 16:692-696, 2000

9. Elangovan C, Singh SP, Gardner P, Snyderman C, TylerKabara EC, Habeych M, et al: Intraoperative neurophysiological monitoring during endoscopic endonasal surgery for pediatric skull base tumors. J Neurosurg Pediatr 17:147-155, 2016

10. Fomichev D, Kalinin P, Kutin M, Sharipov O: Extended transsphenoidal endoscopic endonasal surgery of suprasellar craniopharyngiomas. World Neurosurg 94:181-187, 2016

11. Frazier JL, Chaichana K, Jallo GI, Quiñones-Hinojosa A: Combined endoscopic and microscopic management of pediatric pituitary region tumors through one nostril: technical note with case illustrations. Childs Nerv Syst 24:1469-1478, 2008

12. Gaillard S: The transition from microscopic to endoscopic transsphenoidal surgery in high-caseload neurosurgical centers: the experience of Foch Hospital. World Neurosurg 82 (6 Suppl):S116-S120, 2014

13. Gandhi CD, Christiano LD, Eloy JA, Prestigiacomo CJ, Post KD: The historical evolution of transsphenoidal surgery: facilitation by technological advances. Neurosurg Focus 27(3):E8, 2009

14. Hansen D, Vedantam A, Briceño V, Lam SK, Luerssen TG, Jea A: Health-related quality of life outcomes and level of evidence in pediatric neurosurgery. J Neurosurg Pediatr 18:480-486, 2016

15. Jane JA Jr, Prevedello DM, Alden TD, Laws ER Jr: The transsphenoidal resection of pediatric craniopharyngiomas: a case series. J Neurosurg Pediatr 5:49-60, 2010

16. Kanaan HA, Gardner PA, Yeaney G, Prevedello DM, Monaco EA III, Murdoch G, et al: Expanded endoscopic endonasal resection of an olfactory schwannoma. J Neurosurg Pediatr 2:261-265, 2008

17. Kassam A, Thomas AJ, Snyderman C, Carrau R, Gardner P, Mintz A, et al: Fully endoscopic expanded endonasal approach treating skull base lesions in pediatric patients. $\mathbf{J}$ Neurosurg 106 (2 Suppl):75-86, 2007

18. Kassam AB, Thomas AJ, Zimmer LA, Snyderman CH, Carrau RL, Mintz A, et al: Expanded endonasal approach: a fully endoscopic completely transnasal resection of a skull base arteriovenous malformation. Childs Nerv Syst 23:491-498, 2007

19. Kerr PB, Oldfield EH: Sublabial-endonasal approach to the sella turcica. J Neurosurg 109:153-155, 2008

20. Khalili S, Palmer JN, Adappa ND: The expanded endonasal approach for the treatment of intracranial skull base disease in the pediatric population. Curr Opin Otolaryngol Head Neck Surg 23:65-70, 2015

21. Koc K, Anik I, Ozdamar D, Cabuk B, Keskin G, Ceylan S: The learning curve in endoscopic pituitary surgery and our experience. Neurosurg Rev 29:298-305, 2006

22. Komotar RJ, Starke RM, Raper DM, Anand VK, Schwartz TH: Endoscopic endonasal compared with microscopic transsphenoidal and open transcranial resection of craniopharyngiomas. World Neurosurg 77:329-341, 2012 
23. Locatelli D, Castelnuovo P, Santi L, Cerniglia M, Maghnie M, Infuso L: Endoscopic approaches to the cranial base: perspectives and realities. Childs Nerv Syst 16:686-691, 2000

24. Locatelli D, Massimi L, Rigante M, Custodi V, Paludetti G, Castelnuovo P, et al: Endoscopic endonasal transsphenoidal surgery for sellar tumors in children. Int J Pediatr Otorhinolaryngol 74:1298-1302, 2010

25. Lubbe DE, Fisher-Jeffes N, Semple P: Endoscopic resection of skull base tumours utilising the ultrasonic dissector. $\mathbf{J}$ Laryngol Otol 126:625-629, 2012

26. Mascarella MA, Forghani R, Di Maio S, Sirhan D, Zeitouni $\mathrm{A}, \mathrm{Mohr} \mathrm{G}$, et al: Indicators of a reduced intercarotid artery distance in patients undergoing endoscopic transsphenoidal surgery. J Neurol Surg B Skull Base 76:195-201, 2015

27. Moore RJ, Scherer A, Fulkerson DH: Frontal burr hole approach for neuroendoscopic resection of craniopharyngioma with the NICO Myriad device: report of two cases. Childs Nerv Syst 33:659-664, 2017

28. Munson PD, Moore EJ: Pediatric endoscopic skull base surgery. Curr Opin Otolaryngol Head Neck Surg 18:571-576, 2010

29. Rastatter JC, Snyderman CH, Gardner PA, Alden TD, TylerKabara E: Endoscopic endonasal surgery for sinonasal and skull base lesions in the pediatric population. Otolaryngol Clin North Am 48:79-99, 2015

30. Rigante M, Massimi L, Parrilla C, Galli J, Caldarelli M, Di Rocco C, et al: Endoscopic transsphenoidal approach versus microscopic approach in children. Int J Pediatr Otorhinolaryngol 75:1132-1136, 2011

31. Rougerie J: What can be expected from the surgical treatment of craniopharyngiomas in children. Report of 92 cases. Childs Brain 5:433-449, 1979

32. Salmasi V, Blitz AM, Ishii M, Gallia GL: Expanded endonasal endoscopic approach for resection of a large skull base aneurysmal bone cyst in a pediatric patient with extensive cranial fibrous dysplasia. Childs Nerv Syst 27:649-656, 2011

33. Shibata T, Tanikawa M, Sakata T, Mase M: Urgent optic nerve decompression via an endoscopic endonasal transsphenoidal approach for craniopharyngioma in a 12-month-old infant: a case report. Pediatr Neurosurg 53:182-187, 2018

34. Stapleton AL, Tyler-Kabara EC, Gardner PA, Snyderman $\mathrm{CH}$ : Endoscopic endonasal surgery for benign fibro-osseous lesions of the pediatric skull base. Laryngoscope 125:21992203, 2015

35. Stapleton AL, Tyler-Kabara EC, Gardner PA, Snyderman $\mathrm{CH}$, Wang EW: Risk factors for cerebrospinal fluid leak in pediatric patients undergoing endoscopic endonasal skull base surgery. Int J Pediatr Otorhinolaryngol 93:163-166, 2017
36. Tao ZZ, Chen SM, Liu JF, Huang XL, Zhou L: Paranasal sinuses chordoma in pediatric patient: a case report and literature review. Int J Pediatr Otorhinolaryngol 69:1415-1418, 2005

37. Tatreau JR, Patel MR, Shah RN, McKinney KA, Wheless SA, Senior BA, et al: Anatomical considerations for endoscopic endonasal skull base surgery in pediatric patients. Laryngoscope 120:1730-1737, 2010

38. Yamada S, Fukuhara N, Yamaguchi-Okada M, Nishioka $\mathrm{H}$, Takeshita A, Takeuchi Y, et al: Therapeutic outcomes of transsphenoidal surgery in pediatric patients with craniopharyngiomas: a single-center study. J Neurosurg Pediatr 21:549-562, 2018

39. Youssef CA, Smotherman CR, Kraemer DF, Aldana PR: Predicting the limits of the endoscopic endonasal approach in children: a radiological anatomical study. J Neurosurg Pediatr 17:510-515, 2016

40. Zhan R, Xin T, Li X, Li W, Li X: Endonasal endoscopic transsphenoidal approach to lesions of the sellar region in pediatric patients. J Craniofac Surg 26:1818-1822, 2015

41. Zhan R, Xu G, Wiebe TM, Li X: Surgical outcomes of the endoscopic transsphenoidal route to pituitary tumours in paediatric patients $>10$ years of age: 5 years of experience at a single institute. Arch Dis Child 100:774-778, 2015

\section{Disclosures}

Dr. Hwang: consultant for Medtronic and Canon. Dr. Patel: consultant for Medtronic, Stryker, IntersectENT, and Optinose.

\section{Author Contributions}

Conception and design: Edwards, Quon. Acquisition of data: all authors. Analysis and interpretation of data: Edwards, Quon, Kim. Drafting the article: Edwards, Quon, Kim. Critically revising the article: Edwards, Quon, Kim. Reviewed submitted version of manuscript: all authors. Approved the final version of the manuscript on behalf of all authors: Edwards. Statistical analysis: Kim. Administrative/technical/material support: Edwards, Quon, Kim. Study supervision: Edwards.

\section{Correspondence}

Michael S. B. Edwards: Lucile Packard Children's Hospital, Stanford University School of Medicine, Stanford, CA. edwards9@stanford.edu. 